\title{
Evaluation of induction of labour in a tertiary care hospital
}

\author{
Janupalli Kiran Poornima, Vijayalakshmi K.*, Anuradha C. R., Famida, Sai Latha R.
}

Department of Obstetrics and Gynecology, Chettinad Hospital and Research Institute, Kelambakam, Chennai, Tamil Nadu, India

Received: 19 February 2020

Accepted: 04 March 2020

\section{*Correspondence:}

Dr. Vijayalakshmi K.,

E-mail: viji_kands@yahoo.co.in

Copyright: (C) the author(s), publisher and licensee Medip Academy. This is an open-access article distributed under the terms of the Creative Commons Attribution Non-Commercial License, which permits unrestricted non-commercial use, distribution, and reproduction in any medium, provided the original work is properly cited.

\section{ABSTRACT}

Background: The objective is to evaluate the preferred methods for labor induction, including incidence of caesarean section, operative and normal vaginal delivery rate, need for oxytocin augmentation, and Apgar score at 1 and 5 min. Methods: This was a hospital-based study carried out in 110 inductions of labour during the study period. misoprostol $50 \mathrm{mcg}$ was inserted in posterior fornix of vaginal in cases with PROM and intracervical $0.5 \mathrm{mg}$ Dinoprostone for other causes in whom induction was decided. Maternal and neonatal outcomes were observed. collected data were analyzed using SPSS and MS excel.

Results: Most preferred methods of induction of labour were observed to be Dinoprostone and Misoprostol, augmentation was done by oxytocin. normal delivery rate was $54 \%$ in Dinoprostone gel and $58.3 \%$ in misoprostol group. Caesarean and operative vaginal delivery rates were $42.8 \%, 3 \%$ in Dinoprostone gel group and $33.3 \%, 8.3 \%$ respectively in misoprostol group. Mean Apgar scores were observed to be similar in both methods of induction at $1^{\text {st }}$ and $5^{\text {th }}$ minutes.

Conclusions: It was found that misoprostol had higher percentage of normal and operative vaginal delivery and need for oxytocin augmentation than Dinoprostone. Neonatal outcome as predicted by Apgar score were similar in both groups.

Keywords: Apgar scores, Dinoprostone, Induction of labour, Misoprostol

\section{INTRODUCTION}

Induction of labor (IOL) is an increasingly common obstetric procedure. Recent data demonstrates that over $40 \%$ of primiparous women, and over $30 \%$ of multiparous women, undergo labor induction. ${ }^{1}$ However, when IOL is attempted for a woman with an unfavourable cervix, other interventions used to assist the induction process, such as oxytocin or rupture of membranes, are connected with reduced effectiveness and high failure rates. ${ }^{2}$

A variety of pharmacological and non-pharmacological methods are used for IOL. Pharmacological methods include oxytocin, prostaglandin analogues and smooth muscle stimulants such as herbs or castor oil, whereas non-pharmacological methods include mechanical methods such as digital stretching of cervix and sweeping of membranes, hygroscopic cervical dilators, balloon catheters, artificial rupture of the membranes and nipple stimulation. ${ }^{3}$ Misoprostol is a prostaglandin E1 analogue that was first marketed in the 1980s to prevent and treat peptic ulcer disease. ${ }^{4}$ Misoprostol's low cost, stability in a wide range of temperature and availability in over 80 countries make it particularly useful in resource-poor settings. ${ }^{5}$ Labor induction with Dinoprostone has otherwise been chiefly used with either a $0.5 \mathrm{mg}$ Dinoprostone gel delivered intra-cervically, known as Prepidil [released with US Food and Drug Administration (FDA) approval in 1992 by Pfizer] or a $10 \mathrm{mg}$ controlledrelease vaginal insert known as Cervidil (released with FDA approval in 1995 by Forest Laboratories). ${ }^{6}$ 
Dinoprostone is expensive and requires cold storage to keep the compound chemically stable, which impacts ease of use. ${ }^{7}$

General principles related to the practice of induction of labor ${ }^{8}$ :

- Induction of labor should be performed only when there is a clear medical indication for it and the expected benefits outweigh its potential harms.

- In applying the recommendations, consideration must be given to the actual condition, wishes and preferences of each woman, with emphasis being placed on cervical status, the specific method of induction of labor and associated conditions such as parity and rupture of membranes.

- Induction of labor should be performed with caution since the procedure carries the risk of uterine hyper stimulation and rupture and fetal distress.

- Wherever induction of labor is carried out, facilities should be available for assessing maternal and fetal well-being.

- Women receiving oxytocin, misoprostol or other prostaglandins should never be left unattended.

- Failed induction of labor does not necessarily indicate caesarean section.

- Wherever possible, induction of labor should be carried out in facilities where caesarean section can be performed.

Women may also have preferences about which method is used and may prefer non-pharmacological approaches. On the other hand, women will want their baby to be born safely, and timely induction may improve outcomes for women and babies. ${ }^{9}$ Women facing decisions about induction of labor require up-to-date information about the range of options available, including alternative and complementary methods. ${ }^{10}$

\section{METHODS}

This was a hospital-based observational study which was carried out at Chettinad hospital and research institute, Tamil Nadu during the period from January 2018 to December 2018 for a period of 12 months. The sample population for the study was those patients in whom IOL was decided after admission in the hospital for delivery.

\section{Inclusion criteria}

- Included patient with a full term ( $\geq 37$ weeks), singleton gestation in cephalic presentation. They have been induced for either maternal or obstetric indication.

\section{Exclusion criteria}

- Multiple pregnancies, abnormal presentation, previous caesarean section, unexplained vaginal bleeding during pregnancy, intrauterine death, allergy to prostaglandin. A written informed consent was obtained from all the participants in the study after explaining the consequences.

Before administration of drugs, women were asked to empty the bladder. Bishop's scoring was done. In case of PROM, IOL with misoprostol, $50 \mathrm{mcg}$ was inserted in the posterior fornix of the vagina. Doses of $25 \mu \mathrm{g}$ were repeated every 6 hours according to the requirement of the patient with maximum up to two doses. Further augmentation of labour is done by Oxytocin infusion was started from 5 units given with $500 \mathrm{ml}$ of normal saline at 8 drops per minute. The rate was increased by 8 drops per minute in every $30 \mathrm{~min}$. This was done until a good contraction pattern (three contractions in $10 \mathrm{~min}$ each lasting $>40 \mathrm{~s}$ ) was established maximum up to 60 drops per minute. Uterine contractions (for $10 \mathrm{~min}$ ) and fetal heart rate (for $1 \mathrm{~min}$ ) were monitored hourly. Fetal heart sound (FHS) was monitored every $30 \mathrm{~min}$ in case of infusion of oxytocin. In cases other than PROM, after Bishop's score assessment intracervical $0.5 \mathrm{mg}$ Dinoprostone was inserted and doses repeated every $6^{\text {th }}$ hourly according to the requirement of the patient with maximum up to three doses. Further augmentation of labour is done by oxytocin infusion as mentioned above.

All eligible women were observed for the occurrence of any side effects (vomiting, diarrhoea, pyrexia, tachycardia, tachysystole, hyper stimulation and uterine rupture). After delivery, neonatal condition was observed. Finally, overall maternal and neonatal outcomes were recorded.

\section{Statistical analysis}

Collected data were compiled, managed, analysed and presented using Statistical Package for Social Sciences (SPSS) software and MS Excel. As this was a nonrandomized observational study in which the method of IOL for each woman was determined on clinical grounds, no formal comparisons were made between the treatment groups.

\section{RESULTS}

A total of 110 patients were enrolled in this study after applying inclusion and exclusion criteria. Current study evaluates the most preferred method of IOL in a tertiary care hospital, including incidence of caesarean section, operative and normal vaginal delivery rate, need for oxytocin augmentation, and Apgar score at 1 and 5 min.

Majority of causes belong to age group of 25-30 years $(43.1 \%)$ Table 1. Primigravida were $62.7 \%$ and the rest were multigravida Table $2.36 .4 \%$ were induced at 40 weeks period of gestation Table 3. common indication for IOL was gestational diabetes mellitus followed by oligohydramnios Table 4. Dinoprostone gel was used in $89.1 \%$ of patients Table 5. $34.5 \%$ patients had favourable Bishop's score Table 7. 
Table 1: Distribution of age.

\begin{tabular}{|lll|}
\hline Age (years) & $\mathbf{N}$ & Percentage \\
\hline$<24$ & 43 & $39.1 \%$ \\
\hline $25-30$ & 48 & $43.6 \%$ \\
\hline $31-35$ & 19 & $17.3 \%$ \\
\hline Total & $\mathbf{1 1 0}$ & $\mathbf{1 0 0} \%$ \\
\hline
\end{tabular}

Table 2: Gravidity of population.

\begin{tabular}{|lll|}
\hline Gravida & N & Percentage \\
\hline Primi & 69 & $62.7 \%$ \\
\hline Multi & 41 & $37.3 \%$ \\
\hline Total & $\mathbf{1 1 0}$ & $\mathbf{1 0 0} \%$ \\
\hline
\end{tabular}

Table 3: Period of gestation in weeks.

\begin{tabular}{|l|l|l|}
\hline Weeks & N & Percentage \\
\hline 37 & 14 & $12.7 \%$ \\
\hline 38 & 33 & $30 \%$ \\
\hline 39 & 23 & $20.9 \%$ \\
\hline 40 & 40 & $36.4 \%$ \\
\hline
\end{tabular}

Table 4: Distribution of indication.

\begin{tabular}{|lll|}
\hline Indication & $\mathbf{N}$ & Percentage \\
\hline Pre gestational diabetes & 3 & $2.7 \%$ \\
\hline Gestational diabetes mellitus & 36 & $32.7 \%$ \\
\hline Gestational hypertension & 10 & $9.1 \%$ \\
\hline Pre-eclampsia & 13 & $11.8 \%$ \\
\hline IUGR & 3 & $2.7 \%$ \\
\hline Oligohydramnios & 30 & $27.3 \%$ \\
\hline Prom & 12 & $11 \%$ \\
\hline Rh negative & 3 & $2.7 \%$ \\
\hline
\end{tabular}

Table 5: Mode of induction and oxytocin augmentation.

\begin{tabular}{|c|c|c|c|}
\hline Mode & $\mathbf{N}$ & $\%$ & Augmentation \\
\hline $\mathrm{PGE}_{2}$ & 98 & $89.1 \%$ & $20(20 \%)$ \\
\hline Misoprostol & 12 & $10.9 \%$ & $6(50 \%)$ \\
\hline Total & 110 & $100 \%$ & \\
\hline
\end{tabular}

Table 6: Mode of delivery.

\begin{tabular}{|llll|}
\hline Mode & MISO & PGE $_{2}$ & Total \\
\hline Normal vaginal & $7(11.7 \%)$ & $53(88.3 \%)$ & 60 \\
\hline $\begin{array}{l}\text { Instrumental } \\
\text { vaginal }\end{array}$ & $1(8.7 \%)$ & $3(91.3 \%)$ & 4 \\
\hline LSCS & $4(8.7 \%)$ & $42(91.3 \%)$ & 46 \\
\hline
\end{tabular}

In Dinoprostone gel arm: 54\% had normal vaginal delivery $(\mathrm{n}=53), 3 \%$ had instrumental vaginal delivery $(n=3)$ and $42.8 \%$ had caesarean section $(n=42)$ Table 6 , 7. In Misoprostrol arm: $58.3 \%$ had normal vaginal delivery $(\mathrm{n}=7), 8.3 \%$ had instrumental vaginal delivery $(n=1), 33.3 \%$ had caesarean section $(n=4)$ Table 6,7 .
Table 7: Distribution of outcome in relation to Bishop's score.

\begin{tabular}{|llll|}
\hline Score & Delivery mode & $\mathrm{PGE}_{2}$ & MISO \\
\hline$<6$ & Normal vaginal & $19(86.4 \%)$ & $3(13.6 \%)$ \\
\hline & $\begin{array}{l}\text { Instrumental } \\
\text { vaginal }\end{array}$ & $3(75 \%)$ & $1(25 \%)$ \\
\hline$>6$ & Caesarean & $42(91.3 \%)$ & $4(8.7 \%)$ \\
\hline & Normal vaginal & $34(100 \%)$ & $4(100 \%)$ \\
\hline & $\begin{array}{l}\text { Instrumental } \\
\text { vaginal }\end{array}$ & 0 & 0 \\
\hline & Caesarean & 0 & 0 \\
\hline
\end{tabular}

Table 8: Indication of caesarean.

\begin{tabular}{|lll|}
\hline Indication & PGE $_{2}$ & MISO \\
\hline Fetal distress & 16 & 2 \\
\hline Non progress of labour & 8 & 0 \\
\hline Maternal request & 1 & 0 \\
\hline CPD & 2 & 1 \\
\hline Failed induction & 15 & 1 \\
\hline
\end{tabular}

Table 9: Distribution of mean of Apgar scores.

\begin{tabular}{|llll|}
\hline Mode & Minutes & Mean & Standard deviation \\
\hline PGE $_{2}$ & $1^{\text {st }}$ & 7.6 & 0.758 \\
\hline & $5^{\text {th }}$ & 8.9 & 0.49 \\
\hline MISO & $1^{\text {st }}$ & 7.6 & 0.651 \\
\hline & $5^{\text {th }}$ & 9 & 0.426 \\
\hline
\end{tabular}

Most common indication for emergency caesarean section was fetal distress $(34.7 \%)$ followed by nonprogress of labour $(17.3 \%)$ Table 8 . All patients with favourable Bishop's score had normal vaginal delivery. Mean Apgar scores at $1^{\text {st }}$ minute were 7.6 in both methods and $5^{\text {th }}$ minute were 8.9 in Dinoprostone and 9 in misoprostol group Table 9.

\section{DISCUSSION}

There is a potential risk for the health of mother and infant if pregnancy continues beyond term and because of which IOL is desired. ${ }^{11}$ In a study conducted in Norway, it was found that IOL and post-term pregnancy are the prognostic factors for poor outcome. ${ }^{12}$ Even though routine IOL at 41 weeks of gestation is suggested to reduce perinatal mortality, induction is associated with other obstetric complications. ${ }^{13}$

From this study it is understood that Dinoprostone was quiet frequently used as it provides constant release of medication, can be removed if uterine hyperstimulation occurs. $^{14}$

Sheela et al, demonstrated that post-datism (36\% and $32 \%$ respectively) and $\mathrm{PIH}$ (22\% and $26 \%$ respectively) were most common indications in both groups. ${ }^{15}$ In this study gestational diabetes mellitus was the most common 
reason for IOL followed by oligohydramnios, gestational hypertension, pre-eclampsia, IUGR, PROM, Rh negative pregnancy and other maternal and fetal indications.

Syntocin augmentation was required in $50 \%$ of patients in misoprostol group whereas $20 \%$ of cases required augmentation in Dinoprostone group. It indicates that oxytocin requirement was significantly less in Dinoprostone induced cases. In patients with favorable Bishop's score, all of them progressed and delivered by normal vaginal delivery.

The misoprostol had decreased rate of caesarean section (33.3\%) compared to cerviprime $(42.8 \%), 54 \%$ of patients in misoprost group and $58.3 \%$ in cerviprime group delivered vaginally. This was consistent with the study of Kamal $\mathrm{P}$ et al, and Bhaskar M et al. ${ }^{16,17}$

Most common indication for caesarean section was fetal distress $34.7 \%$ in this study which was consistent with study of Parmar $\mathrm{M}$ et al where $8 \%$ patients in misoprostol and $6 \%$ patients in Dinoprostone undergone caesarean section due to fetal distress. ${ }^{18}$

No significant difference was observed in mean birth weight of neonate in both groups. Mean Apgar score at 1 minute and 5 minutes was also found to be similar in both groups which are 7.6 and 8.9. This is consistent with study of Parmar M et al. ${ }^{18}$

\section{CONCLUSION}

This study revealed that misoprostol had better outcome in view of normal or operative vaginal delivery as compared to Dinoprostone gel. Although it needed more augmentation with oxytocin, it has resulted is more vaginal delivery rate, reduces caesarean section rate and has less chances of failure of induction. More over misoprostol also does not need cold chain storage and is cheaper, both maternal and fetal friendly.

It also observed that Dinoprostone was more preferred as an inducing agent as it has constant release of drug and can be removed in case of onset of uterine hyperstimulation. Both methods had similar outcomes on neonatal outcomes.

\section{Funding: No funding sources} Conflict of interest: None declared

Ethical approval: The study was approved by the Institutional Ethics Committee

\section{REFERENCES}

1. Laughon SK, Zhang J, Grewal J, Sundaram R, Beaver J, Reddy UM. Induction of labor in a contemporary obstetric cohort. Am J Obstet Gynecol. 2012;206:486.e481-489.
2. Crane JM. Factors predicting labor induction success: a critical analysis. Clin Obstet Gynecol. 2006;49:573-84.

3. Hofmeyr GJ, Gülmezoglu AM. Vaginal misoprostol for cervical ripening and induction of labour. Cochrane Database Syst Rev. 2003;1:CD000941.

4. Tang OS, Gemzell-Danielsson K, Ho PC. Misoprostol: pharmacokinetic profiles, effects on the uterus and side-effects. Int J Gynaecol Obstet. 2007;99 (Suppl 2):S160-S167.

5. Shannon CS, Winikoff B. Misoprostol: An Emerging Technology for Women's Health: Report of a Seminar. New York, NY: Population Council; 2004:7-8.

6. Hawkins JS, Wing DA. Current pharmacotherapy options for labor induction. Expert Opin Pharmacother. 2012;13:2005-14.

7. Church S, Van Meter A, Whitfield R. Dinoprostone compared with misoprostol for cervical ripening for induction of labor at term. J Midwifery Womens Health. 2009;54:405-11.

8. World Health Organization. WHO Recommendations for Induction of labour. Available at: http://apps.who.int/iris/bitstream/10665/ 44531/1/9789241501156_eng.pdf. Accessed 15 May 2016.

9. Jozwiak M, Bloemenkamp KW, Kelly AJ, Mol BW, Irion O, Boulvain M. Mechanical methods for induction of labour. Cochrane Database Syst Rev. 2012;14(3):CD001233.

10. Alfirevic Z, Keeney E, Dowswell T, Welton NJ, Medley N, Dias S, et al. Which method is best for the induction of labour? A systematic review, network meta-analysis and cost-effectiveness analysis. Health Technol Assess. 2016;20(65):1-584.

11. Daniel-Spiegel E, Weiner Z, Ben-Shlomo I, Shalev E. For how long should oxytocin be continued during induction of labour?. An Inter J Obstet Gynaecol. 2004;111(4):331-4.

12. Heimstad R, Romundstad PR, Eik-Nes SH, Salvesen KA. Outcomes of pregnancy beyond 37 weeks of gestation. Obstet Gynecol. 2006;108(3):500-8.

13. Heimstad R, Skogvoll E, Mattsson LÅ, Johansen OJ, Eik-Nes SH, Salvesen KÅ. Induction of labor or serial antenatal fetal monitoring in post-term pregnancy: a randomized controlled trial. Obstet Gynecol. 2007;109(3):609-17.

14. ACOG technical bulletin. Induction of labor. Number 217--December 1995 (replaces no. 157, July 1991). American College of Obstetricians Gynecologists: Int J Gynaecol Obstet. 1996;53(1):65-72.

15. Sheela CN, Mhaskar A, George S. Comparison of vaginal misoprostol and oral misoprostol with intracervical dinoprostol gel for induction of labour at term. J Obstet Gynecol India. 2007;57(4):327-30.

16. Patil KP, Swamy MK, Rao Radhika K. Oral Misoprostol vs. intra-cervical cerviprime for cervical ripening and labour induction. J Obstet Gynecol India. 2005;55(2):128-31. 
17. Murthy BK, Arkalgud MS. Misoprostol alone versus a combination of cerviprime and oxytocin for induction of labour. J Obstet Gynecol India. 2006;56(5):413-6.

18. Parmar M, Aherwar R, Jahan I. Comparative study of $25 \mu \mathrm{g}$ vaginal misoprostol $\mathrm{v} / \mathrm{s}$ cerviprime gel for induction of labour at term. Int J Reprod Contracept Obstet Gynecol. 2014;3(4):887-92.
Cite this article as: Poornima $\mathrm{JK}$, Vijayalakshmi $\mathrm{K}$, Anuradha CR, Famida, Latha SR. Evaluation of induction of labour in a tertiary care hospital. Int J Reprod Contracept Obstet Gynecol 2020;9:1361-5. 